PETTERS MELO, Milena; BURCKHART, Thiago. Evoluções do constitucionalismo contemporâneo: a experiência de elaboração do projeto de constituição Islandesa de 2011. Revista Eletrônica Direito e Política, Programa de Pós-Graduação Stricto Sensu em Ciência Jurídica da UNIVALI, Itajaí, v.16, n.1, 10 quadrimestre de 2021. Disponível em: www.univali.br/direitoepolitica - ISSN 1980-7791

\title{
EVOLUÇÕES DO CONSTITUCIONALISMO CONTEMPORÂNEO: A EXPERIÊNCIA DE ELABORAÇÃO DO PROJETO DE CONSTITUIÇÃO ISLANDESA DE 2011
}

\author{
EVOLUTIONS OF CONTEMPORARY CONSTITUTIONALISM: THE CONSTITUTION- \\ MAKING EXPERIENCE OF 2011 ICELAND'S CONSTITUTIONAL PROJECT
}

\author{
Milena Petters Melo' \\ Thiago Burckhart ${ }^{2}$
}

\begin{abstract}
RESUMO
A crise econômica mundial de 2008, que atingiu diretamente a Islândia, impulsionou o aprofundamento da experiência democrática naquele país através da elaboração de um novo projeto de Constituição. Esta experiência contém duas inovações fundamentais: o projeto de Constituição foi escrito mediante crowdsourcing, além da Assembleia Constituinte ter operado em paralelo com a legislatura regular. Tomando isso em consideração, este artigo objetiva analisar descritivamente, partindo da teoria da constituição e da teoria política e utilizando o método dialógico na observação do direito constitucional como uma ciência de textos e contextos, o contexto de elaboração deste projeto, destacando suas peculiaridades, e dimensionando os motivos do seu insucesso de aprovação. Como conclusão são propostas algumas reflexões críticas sobre as potencialidades e os limites da singular experiência islandesa que, contudo, se relacionam com grandes questões que se colocam para o constitucionalismo hodierno, especialmente no que tange à relação entre constitucionalismo e democracia.
\end{abstract}

PALAVRAS-ChAVE: Projeto de Constituição Islandesa de 2011;

Constitucionalismo contemporâneo; Crowdsourcing; Democracia; Crise econômica mundial.

\footnotetext{
1 Doutora em Direito pela Università del Salento (Itália, 2004). Professora Titular de Direito Constitucional da Universidade Regional de Blumenau (FURB). Professora Associada da Academia Brasileira de Direito Constitucional. Professora do Doutorado em Diritto Comparato e Processi di Integrazione da Università degli Studi della Campania Luigi Vanvitelli, Itália. Coordenadora do Núcleo de Estudos em Constitucionalismo, Internacionalização e Cooperação (Constinter-Furb). Coordenadora da sede brasileira do Centro Euroamericano Sulle Politiche Costituzionali (Cedeuam, Itália-Brasil). Blumenau, Santa Catarina, Brasil, Email: mpettersmelo@gmail.com

2 Doutorando em Diritto Comparato e Processi di Integrazione pela Università degli Studi della Campania Luigi Vanvitelli, Itália. Mestre em Direito pela Universidade Federal de Santa Catarina (UFSC, 2019). Pesquisador do Centro Euroamericano Sulle Politiche Costituzionali (Cedeuam, ItáliaBrasil). Pesquisador do Núcleo de Estudos em Constitucionalismo, Internacionalização e Cooperação (Constinter-Furb). Caserta, Campania, Italia, Email: thiago.burckhart@outlook.com
} 
PETTERS MELO, Milena; BURCKHART, Thiago. Evoluções do constitucionalismo contemporâneo: a experiência de elaboração do projeto de constituição Islandesa de 2011. Revista Eletrônica Direito e Política, Programa de Pós-Graduação Stricto Sensu em Ciência Jurídica da UNIVALI, Itajaí, v.16, n.1, 10 quadrimestre de 2021. Disponível em: www.univali.br/direitoepolitica - ISSN 1980-7791

\section{ABSTRACT}

The 2008 global economic crisis, which directly hit Iceland, improved the deepening of the democratic experience in that country through the elaboration of a new constitution project. This experience brings up two fundamental innovations: the Constitution project was written through crowdsourcing, and also the Constituent Assembly operated in parallel with the regular legislature. Taking this in consideration, this article aims to analyze descriptively, starting from constitutional and political theory and using the dialogical method in the observation of constitutional law as a science of texts and contexts, the context of elaboration of this project, highlighting its peculiarities, and dimensioning the reasons for its failure of approval. As a conclusion, some critical reflections are proposed on the potential and limits of this unique experience, which, however, are related to major issues that arise for today's constitutionalism, especially regarding to the relationship between constitutionalism and democracy.

\section{KEY WORDS: 2011 Iceland's constitutional project; Contemporary} constitutionalism; crowdsourcing; Democracy; World's financial crisis.

\section{INTRODUÇÃO}

We, the people who inhabit Iceland, wish to create a just society where every person has equal opportunity. Our diverse origin enriches our society and together we are responsible for the heritage of generations, our country and its history, nature, language and culture ${ }^{3}$.

(Trecho do Preâmbulo do Projeto de Constituição Islandesa de 2011).

O ano de 2008 ficou historicamente marcado pelo advento inesperado da crise financeira global que afetou diversos países do mundo e ainda surte efeitos em determinadas nações. A Islândia foi um dos países mais atingidos, mas também o primeiro que levou à cabo o feito de sair dela. Sua saída ocorreu não por meio da aplicação de medidas de austeridade - o receituário neoliberal do Banco Mundial, Fundo Monetário Internacional e Comissão Europeia -, mas mediante o fortalecimento da experiência democrática, que resultou na elaboração de um novo

\footnotetext{
3 Tradução nossa: "Nós, o povo que habita a Islândia, desejamos criar uma sociedade em que cada pessoa tenha igual oportunidade. Nossa origem diversa enriquece nossa sociedade e juntos somos responsáveis pelo patrimônio de gerações, nosso país e sua história, natureza, linguagem e cultura".
} 
PETTERS MELO, Milena; BURCKHART, Thiago. Evoluções do constitucionalismo contemporâneo: a experiência de elaboração do projeto de constituição Islandesa de 2011. Revista Eletrônica Direito e Política, Programa de Pós-Graduação Stricto Sensu em Ciência Jurídica da UNIVALI, Itajaí, v.16, n.1, 10 quadrimestre de 2021. Disponível em: www.univali.br/direitoepolitica - ISSN 1980-7791

projeto de Constituição mediante crowdsourcing - uma experiência inovadora no âmbito da história do constitucionalismo.

O processo de monetarização da economia capitalista ${ }^{4}$ foi o ponto central da crise de 2008. Tratou-se, naquele momento, da explosão da bolha imobiliária, que impediu o circuito "normal" de capital5. Na Islândia, o desemprego alcançou a casa dos $12 \%$ da população em maio de $2008^{6}$, no momento auge da crise econômica mundial, que foi gerada em decorrência da quebra de bancos mundiais como o Lehman Brothers ${ }^{7}$. O colapso ainda levou a Islândia a perder $8 \%$ de sua riqueza em dois anos, e somente conseguiu adentrar em processo de recuperação da crise a partir de 2011.

Como bem descreve Gylfason, "crises precede constitutions" ${ }^{8}$, ou seja, os momentos de crise e de ruptura com a ordem posta precedem a feitura de novas Constituições, de novos ordenamentos jurídicos, legitimados por um novo acordo político. A história do constitucionalismo é claramente marcada pela reinvenção das constituições nos contextos de crise que, evidentemente, legitima a ruptura da ordem antiga e o desenho de uma nova. Nesse sentido, a experiência islandesa de elaboração do novo texto constitucional é instigante para a reflexão sob o ponto de vista teórico-constitucional e teórico-político, especialmente no que tange ao processo de elaboração do projeto de Constituição de 2011 - apesar de não ter sido ainda formalmente promulgada.

Desse modo, partindo da teoria da constituição, da teoria política, com aportes da sociologia jurídica, e utilizando o método dialógico na observação do direito

\footnotetext{
${ }^{4}$ Nesse sentido, Marilena Chauí ao tratar das características do neoliberalismo destaca a passagem da economia ao monetarismo, cf. CHAUÍ, Marilena. Uma nova classe trabalhadora. In: SADER, Emir. Lula e Dilma: 10 anos de governos pós-neoliberais no Brasil. Rio de Janeiro: FLACSO, 2013, p. 123134. Nesse mesmo sentido, Milton Santos define o processo de globalização e de crescente expansão e financeirização do capitalismo como um "globaritalismo", um sistema e um processo totalitário. Para aprofundamentos, ver: SANTOS, Milton. Por uma outra globalização. Record: Rio de Janeiro, 2001.

5 Para aprofundamentos, ver: HARVEY, David. The enigma of capital: and the crisis of capitalism. London: Profile, 2010.

6 MONTEIRO, Hugo Bragança. Como a Islândia saiu da crise. Económico, Lisboa, 19 Out. 2012. Disponível em: http://economico.sapo.pt/noticias/como-a-islandia-saiu-da-crise 154357.html.

$7 \mathrm{Em}$ uma perspectiva mais profunda, pode-se afirmar que a crise econômica de 2008 convida a repensar o sistema econômico mundial e o modelo de desenvolvimento hegemônico.

8 Tradução nossa: "as crises precedem as Constituições". GYLFASON, Thorvaldur. From collapse to Constitution: the case of Iceland. CESifo Working Paper n. 3770, p. 1.
} 
PETTERS MELO, Milena; BURCKHART, Thiago. Evoluções do constitucionalismo contemporâneo: a experiência de elaboração do projeto de constituição Islandesa de 2011. Revista Eletrônica Direito e Política, Programa de Pós-Graduação Stricto Sensu em Ciência Jurídica da UNIVALI, Itajaí, v.16, n.1, 10 quadrimestre de 2021. Disponível em: www.univali.br/direitoepolitica - ISSN 1980-7791

constitucional como uma ciência de textos e contextos, este artigo tem por objetivo analisar descritivamente o contexto de nascimento do texto projeto constitucional islandês de 2011. Objetiva também sublinhar as inovações que essa experiência traz para o patrimônio comum do constitucionalismo democrático, destacando peculiaridades do texto do projeto, bem como escrutinar os entraves políticos que impediram, e ainda impedem, sua efetiva promulgação. O artigo, portanto, dividese em três tópicos: I. Histórico e contextualização do caso islandês; II. Os marcos da nova Constituição e inovações no processo de elaboração: crowdsourcing e Assembleia Constituinte em paralelo ao Parlamento; III - Motivos do insucesso em sua promulgação.

Importante observar que quando no título do artigo se alude às "evoluções" do constitucionalismo contemporâneo, a intenção é referir os "movimentos" do constitucionalismo na sua dinâmica que envolve avanços e retrocessos, não uma evolução progressiva e expansivamente no sentido de "progresso". Nesse sentido, ao final do artigo são propostas algumas reflexões críticas sobre os limites e potencialidades da recente e singular experiência islandesa. Reflexões, estas, que se colocam de forma mais ampla ao próprio constitucionalismo contemporâneo, especialmente no que toca as suas relações com a democracia.

\section{HISTÓRICO E CONTEXTUALIZAÇÃO DO CASO ISLANDÊS}

A Islândia é um país jovem e pequeno situado no extremo norte do Oceano Atlântico. A ilha tornou-se uma nação soberana ao findar a Primeira Guerra Mundial, quando formou juntamente com o Reino da Dinamarca uma União Pessoal $^{9}$. No ano de 1944 a Islândia tornou-se uma República, forma de governo em que o país continua organizado até os dias atuais. Atualmente, o país possui uma população de pouco mais de 320.000 habitantes, onde cerca de um terço vive na capital do país: Reiquiavique.

\footnotetext{
9 "In the so called Union Act a treaty between Iceland and Daenmark from 1918 Iceland became sovereign a state in a monarchial union with the state of Denmark." ÁRNASON, Ágúst Thór. A Review of the Icelandic Constitution: popular sovereignty of political confusion. Tijdschrift voor Constitutioneel Recht, v. 2, n. 3, p. 342-351, 2011.
} 
PETTERS MELO, Milena; BURCKHART, Thiago. Evoluções do constitucionalismo contemporâneo: a experiência de elaboração do projeto de constituição Islandesa de 2011. Revista Eletrônica Direito e Política, Programa de Pós-Graduação Stricto Sensu em Ciência Jurídica da UNIVALI, Itajaí, v.16, n.1, 10 quadrimestre de 2021. Disponível em: www.univali.br/direitoepolitica - ISSN 1980-7791

No mesmo ano de fundação da república, a Islândia promulgou sua primeira Constituição como Estado soberano. Entretanto, o texto constitucional foi uma "cópia" da então Constituição dinamarquesa, sem grandes inovações ou inserção de novos instrumentos.

A Constituição foi projetada primeiramente para ter vigência temporária, até o momento do reestabelecimento da paz e da nova ordem global com o fim da guerra. A promessa não foi, evidentemente, cumprida. Este ato foi negligenciado pelos representantes políticos e pela sociedade civil, mesmo diante da promulgação de novas Constituições na Itália (1948) e Alemanha (1949) e em diversos outros países da Europa nos anos subsequentes ao fim da segunda guerra mundial - momento marcado pela emergência de um novo paradigma do constitucionalismo ${ }^{10}$, que em função do fortalecimento dos direitos e garantias fundamentais, aliadas à tutela internacional dos direitos humanos, levou a segunda metade do século passado a ficar conhecida como a "Era dos Direitos"11.

Ao longo da história da Islândia, foram poucas as modificações realizadas no texto da Constituição de 1944, de modo que "the debate on the revision of the constitution started when the 30th anniversary of the Republic approached on $1974^{\prime 12}$. Nesse sentido, foram poucos os momentos de reflexão social e política em prol da reformulação de uma nova Constituição. Nos anos 1990 e no início do século XXI a Constituição islandesa passou por breves processos de modificação,

\footnotetext{
10 Alguns autores, seguindo a trilha de Luís Roberto Barroso passaram a identificar este novo paradigma como "Neconstitucionalismo"; cf. BARROSO, Luis Roberto. Neoconstitucionalismo e constitucionalização do Direito: o triunfo tardio do direito constitucional no Brasil. Revista de Direito Administrativo, Rio de Janeiro, v. 240, p. 1-42, abr. 2005. No entanto, em função do uso problemático deste conceito, parece mais acertado falar de "constitucionalismo democrático do pósguerra". A propósito, consultar: MELO, Milena Petters. As recentes evoluções do constitucionalismo na América Latina: neoconstitucionalismo? In WOLKMER, Antonio Carlos; MELO, Milena Petters (Org.). Constitucionalismo Latino-Americano: tendências contemporâneas. Curitiba: Juruá, 2013.

${ }^{11}$ Conforme definição clássica de BOBBIO, Norberto. L'età dei diritti. Torino: Einaudi 1990. Ou como propõe Ackerman, referindo-se aos últimos sessenta anos como a "wave of constitutionalism" ACKERMAN, Bruce. The Rise of World Constitutionalism. Virginia Law Review, v. 83, n. 4, p. 771$797,1997$.

12 Tradução nossa: "o debate sobre a revisão da Constituição começou quando do $30^{\circ}$ aniversário da República se aproximava em 1974". ÁRNASON, Ágúst Thór. A Review of the Icelandic Constitution: popular sovereignty of political confusion. Tijdschrift voor Constitutioneel Recht, v. 2, n. 3,2011, p. 345.
} 
PETTERS MELO, Milena; BURCKHART, Thiago. Evoluções do constitucionalismo contemporâneo: a experiência de elaboração do projeto de constituição Islandesa de 2011. Revista Eletrônica Direito e Política, Programa de Pós-Graduação Stricto Sensu em Ciência Jurídica da UNIVALI, Itajaí, v.16, n.1, 10 quadrimestre de 2021. Disponível em: www.univali.br/direitoepolitica - ISSN 1980-7791

com a inclusão de direitos fundamentais e a mudança do sistema cameral do Congresso.

In 1991 the constitution was amended to change from bicameral system into a single chamber system. In 1995 the human rights provisions of the constitution were revised constituting by far the most important constitutional change since the foundation of the Republic in 1944. [...] A new constitutional committee was formed in 2003 and met regularly for a couple of years without yielding any results at all ${ }^{13}$.

Partindo do pressuposto de que as Constituições surgem a partir de contextos de crise social e política, como afirma Gylfason e Jon Elster ${ }^{14}$, não há que se negar que a sociedade islandesa passou por crises tanto no âmbito social, político e/ou econômico desde a sua fundação como república em 1944. No entanto, a crise financeira de 2008 - que não foi somente econômica, mas também política - foi a primeira que balançou profundamente a estrutura político-econômica e impulsionou a sociedade civil a reivindicar uma nova Constituição.

A crise econômica, resultado dos impactos do desenfreado neoliberalismo especialmente no contexto de privatizações ocorridas a partir das décadas de 1980/1990 no país, fez com que grande parcela da população islandesa repensasse o modelo de desenvolvimento, em prol de um desenvolvimento não meramente econômico que mira a qualidade de vida e a sustentabilidade, calcado nas multifacetadas dimensões: social, cultura, ecológica, ambiental, territorial, econômica, política nacional e política internacional (um modelo de "desenvolvimento sustentável", seguindo a definição de Ignacy Sachs ${ }^{15}$ ).

\footnotetext{
13 Tradução nossa: "Em 1991 a Constituição foi emendada para mudar o sistema político de bicameral para unicameral. Em 1995 as previsões relativas aos direitos humanos da Constituição foram revisados, constituindo a primeira, de longe, a maios importante mudança constitucional desde a fundação da República em 1944 [...] Um novo comitê constitucional fora formado em 2003, com regulares encontros por vários anos, mas sem propor algum resultado ainda". Ibidem. p. 345

14 Cf. ELSTER, Jon. Forces and mechanisms in the Constitutional-Making process. Duke Law Journal, v. 45, n. 364, 1995. Nesse mesmo sentido, adverte David Landau: "Constitution-making is often undertaken in situations in which existing political institutions have broken down, and the constitution-making process itself is often a challenge to the legitimacy of remaining institutions". LANDAU, David. Constitution-Making Gone Wrong. Alabama Law Review, v. 64, n. 5, 2013, p. 925.

${ }^{15}$ SACHS, Ignacy. Caminhos para o desenvolvimento sustentável. Rio de Janeiro: Garamond, 2002.
} 
PETTERS MELO, Milena; BURCKHART, Thiago. Evoluções do constitucionalismo contemporâneo: a experiência de elaboração do projeto de constituição Islandesa de 2011. Revista Eletrônica Direito e Política, Programa de Pós-Graduação Stricto Sensu em Ciência Jurídica da UNIVALI, Itajaí, v.16, n.1, 10 quadrimestre de 2021. Disponível em: www.univali.br/direitoepolitica - ISSN 1980-7791

Buscou-se, portanto, repensar também os ditames do neoliberalismo, que, em escala global e nos seus impactos nos diferentes países, pode ser observado como "un proyecto autoritario que pretendía disimularse en la supuesta racionalidad y anonimato del marcado"16.

Com o ranger da crise em 2008 e a falência do banco Islandês Icesave, o governo islandês foi pressionado pelos governos do Reino Unido e Holanda a "to compensate the citizens who deposited money in British and Dutch branches of the Icelandic bank Icesave"17. Desse modo, o governo islandês assinou em 2009 um acordo com os respectivos governos desses países para efetuar todos os pagamentos com orçamento público, de modo que cada cidadão islandês pagasse pelo período de quinze anos a quantia de 130 euros mensais, como forma de compensação ${ }^{18}$.

Esta medida, em razão de sua impopularidade, despertou a revolta nas ruas das maiores cidades, com o fito de reivindicar o não pagamento da dívida por parte da população. Deu-se início à "revolução dos potes e panelas", que resultou em um referendo no início de 2010, em que o governo consultou o povo sobre o pagamento ou não da referida dívida. Nesta consulta, 93,2\% da população islandesa recusou-se a pagá-la ${ }^{19}$.

Logo após o referendo, mirando ao prisma da mudança social, política e econômica, grande parcela da população islandesa exigiu a feitura de uma nova Constituição, que não tinha sido realizada desde 1944. Mediante atos de protesto e reivindicação popular, "a national election of representatives of the Constitutional Assembly was held in November 2010. There were 523 candidates competing for

\footnotetext{
16 BORON, Atillio. El neoliberalismo armado. In: SADER, Amir; GENTILLI, Pablo. La trama del neoliberalismo: mercado, crisis y exclusión social. CLACSO - Consejo Latinoamericano de Ciencias Sociales: Buenos Aires, 2003. p. 5.

17 Tradução nossa: "para compensar os cidadãos que depositaram dinheiro em agências britânicas e holandesas do banco islandês Icesave". DANIELSSON, Jon. The first casualty of the crisis: Iceland. In: FELTON, Andrew; REINHART, Carmem M. (Org.). The First Global Financial Crisis of the $\mathbf{2 1}^{\text {st }}$ Century. Centre of Economic Policy Reserch (cepr): A Vox EU.ogr Publication, London, 2008.

18 SANTAYANA, Mauro. O plebiscito Islandês e o silêncio das mídias. Rio de Janeiro: Opera Mundi, 21 de outubro de 2012. Disponível em: $<$ http://operamundi.uol.com.br/conteudo/opiniao/25002/o+plebiscito+islandes+e+os+silencios+d a+midia.shtml>, acesso em 22 de fevereiro de 2018.

${ }_{19}$ MUEHLBRONNER, Kathrin. Iceland: Outcome of referendum on Icesave likely to impact sovereign ratings. Global Sovereign, London, 23 de fevereiro de 2013.
} 
PETTERS MELO, Milena; BURCKHART, Thiago. Evoluções do constitucionalismo contemporâneo: a experiência de elaboração do projeto de constituição Islandesa de 2011. Revista Eletrônica Direito e Política, Programa de Pós-Graduação Stricto Sensu em Ciência Jurídica da UNIVALI, Itajaí, v.16, n.1, 10 quadrimestre de 2021. Disponível em: www.univali.br/direitoepolitica - ISSN 1980-7791

25 seats if competition is the right word"20, o que evidencia a grande participação social neste processo.

Com a proposta de o povo e não o Congresso (Althingi $i^{21}$ ) escrever a Constituição, todo cidadão pôde submeter sua candidatura a fazer parte do Conselho Constitucional, uma espécie de Assembleia Constituinte, responsável por redigir a nova Constituição e posteriormente submetê-la a referendo popular. Nesse sentido, pode-se compreender a profunda crise de legitimidade democrática que alicerçava a subjetividade dos islandeses, e devido a isso a nova Constituição prevê profundas transformações no âmbito da cidadania ativa, pautada na reinterpretação da soberania popular com base no accountability social e na cooperação para proteção dos bens comuns, na preservação da natureza e da biodiversidade e na equidade intergeracional ${ }^{22}$ como novas bases de interação político-social e econômica.

Neste sentido, como se observa, o nascimento do projeto de Constituição de 2010 permeia o contexto de crise econômica vivenciada em 2008, culminando em uma crise política que atingiu o país. Entretanto, apesar da nova Constituição ter sido aprovada em referendo por $66 \%$ da população ${ }^{23}$, ela ainda necessita da aprovação do Althingi para ser efetivamente promulgada. Pelo fato da nova Constituição romper com uma série de questões políticas e econômicas como descrito acima, diversas correntes conservadoras do Parlamento islandês buscam sua não aprovação pelo Althingi, como será tratado com mais profundidade adiante. Diante disso, a crise política instaurada em 2008, que em grande medida ainda permanece vigente no país, pode ser um empecilho para a promulgação desta Constituição e a consequente posta em cena de reformas em diversos segmentos.

\footnotetext{
20 Tradução nossa: "uma eleição nacional de representantes de Assembleia Constituinte foi realizada em novembro de 2010. Haviam 523 candidatos competindo por 25 cadeiras, sendo competição a palavra certa para definir o processo" GYLFASON, Thorvaldur. From collapse to Constitution: the case of Iceland. p. 13.

${ }^{21}$ Althingi é o nome pela qual é popularmente conhecido o Congresso islandês.

22 Ou seja, preservando os direitos e prerrogativas das futuras gerações. A propósito e para aprofundamentos consultar: WEISS, Braown (ed.). Chapter 12 in Environmental change and international law: New challenges and dimensions. Tokyo: United Nations University Press, 1992. 23 ISLÂNDIA, Ministério do Interior. Advertisement of the results of the referendum on 20th October 2012. Disponível em

http://www.kosning.is/thjodaratkvaedagreidslur2012/english/nr/7993 >
} 
PETTERS MELO, Milena; BURCKHART, Thiago. Evoluções do constitucionalismo contemporâneo: a experiência de elaboração do projeto de constituição Islandesa de 2011. Revista Eletrônica Direito e Política, Programa de Pós-Graduação Stricto Sensu em Ciência Jurídica da UNIVALI, Itajaí, v.16, n.1, 10 quadrimestre de 2021. Disponível em: www.univali.br/direitoepolitica - ISSN 1980-7791

\title{
2. MARCOS JURÍDICOS E INOVAÇÕES NO PROCESSO DE ELABORAÇÃO: CROWDSOURCING E ASSEMBLEIA CONSTITUINTE EM PARALELO AO PARLAMENTO
}

Tendo em vista a criação de instrumentos de participação direta na elaboração do projeto da nova Constituição islandesa, bem como a criação do Conselho Constitucional composto por 25 membros do povo responsável por redigir o texto constitucional, foram estabelecidos grupos de trabalho que ficaram responsáveis pela escrita de partes da Constituição de acordo com respectivos temas.

\begin{abstract}
At the time of writing the Constitutional Council has established three working groups $A, B$ and $C$ each dealing with different issues. Working group $A$ will be dealing with basic constitutional values; citizenship; the Icelandic language as the official language of the nation; the structure of the Constitution; natural resources; the environment; human rights and the national church (evangelic Lutheran). Group B will be dealing with the pillars of the constitution of the Republic; the role and power of the president of the Republic; the role and power of the Althingi parliament; the government; the functions of the president of the Republic and of the ministers; and the projects and the purpose of the administration; and the municipalities. Finally, group $\mathrm{C}$ will be dealing with a constitutional council (advisory council for the president of the republic, the Parliament and the government); referendum and other forms of direct democracy; changes of the constitution by referendum; the independence of the courts and their role as surveillance instance and as guaranty against misuse of power by the administration and the legislator; parliament elections; the electoral system; the parliamentarians; bilateral agreements and foreign affairs ${ }^{24}$.
\end{abstract}

\footnotetext{
24 Tradução nossa: "Durante a redação do projeto de Constituição, o Conselho Constitucional estabeleceu três grupos de trabalho A, B e C, cada um trabalhando com diferentes questões. O grupo de trabalho A ficou responsável pelos valores constitucionais básicos; cidadania; a língua islandesa como a língua oficial da nação; a estrutura da Constituição; recursos naturais; o ambiente; direitos humanos e a igreja nacional (evangélico-luterana). O Grupo B ficou responsável pelos pilares da constituição da República; o papel e o poder do presidente da República; o papel e poder do parlamento Althingi; o governo; as funções do presidente da República e dos ministros; e os projetos e o propósito da administração pública; e os municípios. Finalmente, o grupo C ficou responsável pelo conselho constitucional (conselho consultivo para o presidente da República, o Parlamento e o governo); referendo e outras formas de democracia direta; mudanças da constituição por referendo; a independência dos tribunais e o seu papel como instância de vigilância e como garantia contra a má utilização do poder pela administração e pelo legislador; eleições parlamentares; o sistema eleitoral; os parlamentares; acordos bilaterais e assuntos externos". ÁRNASON, Ágúst Thór. A Review of the Icelandic Constitution: popular sovereignty of political confusion. Tijdschrift voor Constitutioneel Recht, v. 2, n. 3, 2011, p. 351.
} 
PETTERS MELO, Milena; BURCKHART, Thiago. Evoluções do constitucionalismo contemporâneo: a experiência de elaboração do projeto de constituição Islandesa de 2011. Revista Eletrônica Direito e Política, Programa de Pós-Graduação Stricto Sensu em Ciência Jurídica da UNIVALI, Itajaí, v.16, n.1, 10 quadrimestre de 2021. Disponível em: www.univali.br/direitoepolitica - ISSN 1980-7791

A partir da sinergia entre os grupos de trabalho, o projeto da nova Constituição islandesa foi dividido em nove capítulos, como segue: I - Elementos básicos; II Direitos humanos; III - Althingi; IV - Presidente da Islândia; V - Ministros e Ministérios; VI - O judiciário; VII - Governos locais; VIII - Relações exteriores; IX - Provisões finais. Foram significativas as transformações oriundas do novo projeto de Constituições islandesa ${ }^{25}$ quando comparado com a Constituição de 1944, sobretudo no que se refere à proteção da natureza e accountability social. Isso permite afirmar que as inovações substanciais do novo projeto de Constituição islandesa dizem respeito à tutela do meio ambiente e aos mecanismos de democracia direta.

Nesse sentido, a nova Constituição aborda uma nova perspectiva no que tange ao accountability social. O artigo 15 trata do direito à informação, onde é garantido a cada cidadão o direito à coletar e disseminar informações de cunho políticogovernamental. A administração pública do país deve assegurar a transparência em suas ações, além de terem o dever de preservar documentações como atas de reuniões para fins de coleta e pesquisa. Ligado a isso, o artigo 16 trata da liberdade de imprensa, sendo necessária a garantia de independência e transparência da mídia. Todas as reuniões do Althingi islandês devem seguir o princípio da publicidade, devendo ser abertas à participação do público, pelo qual podem expor suas ideias com relação ao que está sendo votado, de acordo com o artigo 55. Além disso, é necessário que se recolha a assinatura de dez por cento da população islandesa para a realização de referendo de determinada lei aprovada no Althingi, contribuindo para a construção da cultura do controle político-social.

Já no que tange a proteção à natureza - questão que mais deflagrou discussões , a nova Constituição traz no âmbito do capítulo sobre os Direitos Humanos

\footnotetext{
25 Tradução nossa: "Na nova constituição, o número de artigos aumentou em um terço em relação à antiga Constituição, para 114 artigos em nove capítulos. A estrutura foi, além disso, completamente rearranjada. O capítulo sobre direitos humanos foi estendido para incluir os direitos sociais e civis e foi adiantado para enfatizar sua importância. Um novo capítulo sobre a proteção natural é introduzido, incluindo um artigo dizendo que os recursos naturais que não são propriedade privada devem ser propriedade conjunta e perpétua da nação". Cf. BERGMANN, Eirikur. Reconstituting Iceland: constitutional reform caught in a new critical order in the wake of crisis. Working paper prepared in the conference Political Legitimacy and the Paradox of Regulation. Presented in the workshop Crowd-pleasers or key janglers? The impact of drops in political legitimacy on democratic reform and their consequences. Leiden University, January 24-25, 2013. p. 10.
} 
PETTERS MELO, Milena; BURCKHART, Thiago. Evoluções do constitucionalismo contemporâneo: a experiência de elaboração do projeto de constituição Islandesa de 2011. Revista Eletrônica Direito e Política, Programa de Pós-Graduação Stricto Sensu em Ciência Jurídica da UNIVALI, Itajaí, v.16, n.1, 10 quadrimestre de 2021. Disponível em: www.univali.br/direitoepolitica - ISSN 1980-7791

(Capítulo II) quatro artigos que tratam sobre a questão ambiental. O artigo 33 aborda a natureza e meio ambiente da Islândia, e coloca que a natureza constitui a base da vida no país, devendo todos respeitar e protegê-la. A diversidade da vida deve ser mantida e protegida pela população das diversas áreas, além de que o uso dos recursos naturais que venham a causar danos significativos à natureza deve ser evitado ao máximo, respeitando o direito a uma natureza equilibrada das futuras gerações.

Os recursos naturais da Islândia que até então não pertencem à propriedade privada serão propriedade conjunta e permanente da nação, não sendo permitida sua alienação ou eventual penhora, como prevê o artigo 34. Nesse sentido, é superada a lógica mercantil em relação aos recursos naturais presentes na Islândia, onde estes passam a ser concebidos como bens comuns de todos, não podendo haver a sua privatização. Além disso, este mesmo artigo prevê que o desenvolvimento sustentável e o interesse público devem ser utilizados como horizontes para o país, superando também o desenfreado crescimento que pressupõe o modelo neoliberalista.

Todo novo empreendimento e construção deve ser acompanhado de estudo de impacto ambiental, e diante disso, caso esta nova construção venha a surtir um grande impacto na natureza, cabe à população votar se este será ou não construído, conforme dispõe o artigo 35.

Além disso, a nova Constituição também trata da proteção aos animais. O artigo 36 prevê que todos os animais devem ser protegidos de mal tratos e aqueles que se encontram em risco de extinção devem ser protegidos, de acordo com legislação regulamentadora.

É nesse sentido que se enveredam as transformações no âmbito do constitucionalismo islandês. Estas contribuem diretamente para o patrimônio comum do constitucionalismo democrático e, em determinados pontos, assemelham-se às transformações constitucionais que recentemente ocorreram na América Latina, especialmente em comparação com a Constituição do Equador, de 2008, e da Bolívia, de 2009, no que se refere aos direitos da natureza e aos direitos de participação política. 
PETTERS MELO, Milena; BURCKHART, Thiago. Evoluções do constitucionalismo contemporâneo: a experiência de elaboração do projeto de constituição Islandesa de 2011. Revista Eletrônica Direito e Política, Programa de Pós-Graduação Stricto Sensu em Ciência Jurídica da UNIVALI, Itajaí, v.16, n.1, 10 quadrimestre de 2021. Disponível em: www.univali.br/direitoepolitica - ISSN 1980-7791

Numa perspectiva histórica, pode-se dizer que o constitucionalismo, entendido como um movimento jurídico-político-cultural, passa a ser ressignificado - no âmbito de sua compreensão como processo - a partir das condicionantes políticas e culturais que influenciam diretamente as sociedades. Se, como já afirmado, as crises precedem as constituições, é no contexto sócio-político-cultural que as inovações tornam-se possíveis, introjetando no plano jurídico-constitucional os novos valores, perspectivas, ações, intenções e práticas.

Nesse contexto, torna-se impossível dissociar a era da informação ${ }^{26}$ dos processos políticos fundamentais. A era da informação proporciona uma potencialidade de informação, transparência e participação de uma gama maior de cidadãos na tomada de decisões políticas, ampliando o leque de propostas e de possibilidades. Ao longo da história do constitucionalismo, é perceptível que só recentemente após a Segunda Guerra Mundial - houve uma abertura no campo da participação cidadã no processo de construção de Constituições. Em geral, as Assembleias Constituintes tendem a contar com um baixo nível de participação social, além de uma falta de transparência na tomada de decisões que irão afetar diretamente a vida de uma nação pelos anos, ou décadas, seguintes.

A experiência islandesa, nesse sentido, inova em uma questão central no processo político. Pela primeira vez na história política uma Constituição foi redigida mediante crowdsourcing. Trata-se de uma experiência inovadora no âmbito do constitucionalismo democrático, um recurso que marca a abertura do processo de escrita da Constituição para a nação, de modo que qualquer cidadão pôde efetivamente contribuir de forma direta. Nesse sentido, Hélène Landemore afirma que:

Iceland's recent experiment in redrafting its constitution has challenged the assumptions that a constitutional process needs to be exclusive and opaque. In 2013 the country came close to passing into law the world's most inclusively and transparently written constitutional text. This experiment-sometimes dubbed the "crowdsourced constitution"- should prove inspirational for people

${ }^{26}$ No contexto definido por CASTELLS, Manuel. A sociedade em rede. $8^{a}$ ed. Trad. Roneide Venancio Majer. Rio de Janeiro: Paz e Terra, 2007. 
PETTERS MELO, Milena; BURCKHART, Thiago. Evoluções do constitucionalismo contemporâneo: a experiência de elaboração do projeto de constituição Islandesa de 2011. Revista Eletrônica Direito e Política, Programa de Pós-Graduação Stricto Sensu em Ciência Jurídica da UNIVALI, Itajaí, v.16, n.1, 10 quadrimestre de 2021. Disponível em: www.univali.br/direitoepolitica - ISSN 1980-7791

around the globe intent on writing, or re-writing, their own social contract ${ }^{27}$.

A inovação foi arquitetada pelo Conselho Constitucional responsável pela elaboração do Projeto, de modo que a participação no processo deliberativo ocorreu por meio da internet, através de redes sociais como Facebook e Twitter, além da tradicional correspondência. O Google software também foi utilizado pelo Conselho, sobretudo o Google Docs na escrita de textos por comitês. Ademais, todas as reuniões do Conselho Constitucional foram transmitidas em televisão, permitindo haver um controle social efetivo das deliberações públicas tomadas pelo Conselho 28 .

Este processo representa uma confluência e não divergência no que tange à relação entre constitucionalismo e democracia. Trata-se, como afirmou Gilfasson e Anne, de um "experiment in democracy", de modo que "the Icelandic process, which has drawn considerable academic attention, is not the first example of popular involvement in constitution-making, but it is probably the most deliberate, the most democratic, and the most 'global' one to date"29. Isso fornece elementos para pensar a e-democracia, uma democracia que se aprimora adotando

\footnotetext{
27 Tradução nossa: "O recente experimento ocorrido na Islândia de reformulação de sua Constituição desafiou os pressupostos de que um processo constitucional precisa ser exclusivo e opaco. Em 2013, o país chegou perto de aprovar o texto constitucional mais inclusivo e transparente do mundo. Esta experiência - às vezes apelidada de "constituição participativa" - deve ser inspiradora de pessoas de todo o mundo que pretendem escrever ou reescrever seu próprio contrato social". LANDEMORE, Hélène. Inclusive Constitution-Making: the Icelandic experiment. Journal of Political Philosophy, Hoboken, v. 23, n. 2, pp. 166-191, 2015.

${ }^{28}$ Nas palavras de Eirikur Bergamann (tradução nossa): "Por meio dos meios de comunicação social como Facebook e Twitter, o Conselho atraiu cerca de 3.600 postagens individuais, além de 370 propostas formais por meio de correspondência mais tradicional. O Conselho também abriu seus documentos de trabalho on-line e os membros puderam explicar seus feitos em inúmeras entrevistas. Todas as reuniões foram transmitidas na TV e por webcast direto. O fato de os islandeses serem os maiores usuários da Internet no mundo, com $95 \%$ da população conectada ajudou sobremaneira nesse aspecto. Os membros do Conselho até postaram seus números de telefone privados em seu site com um incentivo para as pessoas entrarem em contato." BERGAMANN, Eirikur. Working paper prepared in the conference Political Legitimacy and the Paradox of Regulation. Presented in the workshop Crowd-pleasers or key janglers? The impact of drops in political legitimacy on democratic reform and their consequences.Leiden University, January 24-25, 2013.

29 Tradução nossa: "o processo islandês, que atraiu considerável atenção acadêmica, não é o primeiro exemplo de envolvimento popular na elaboração de constituição, mas é provavelmente o mais deliberado, o mais democrático e o mais "global" até hoje". GYLFASON, Thorvadur; MEUWESE, Anne. Digital Tools and the Derailment of Iceland's New Constitution. CESifo Working Paper, n. 5997, category 2, Public Choice, july 2016. p. 02.
} 
PETTERS MELO, Milena; BURCKHART, Thiago. Evoluções do constitucionalismo contemporâneo: a experiência de elaboração do projeto de constituição Islandesa de 2011. Revista Eletrônica Direito e Política, Programa de Pós-Graduação Stricto Sensu em Ciência Jurídica da UNIVALI, Itajaí, v.16, n.1, 10 quadrimestre de 2021. Disponível em: www.univali.br/direitoepolitica - ISSN 1980-7791

mecanismos digitais como elementos positivos na dinâmica de participação popular na esfera de decisões ${ }^{30}$.

Outra inovação do processo de elaboração do Projeto de Constituição islandesa diz respeito à concomitância do processo de elaboração da Constituição com o funcionamento do Congresso Nacional. Tanto a Assembleia Constituinte quanto o Conselho Constitucional (que substituiu a Assembleia Constituinte), ocorreram de forma concomitante ao processo legislativo do Parlamento islandês. Nesse contexto, Alan Renwick destaca a peculiaridade desta experiência: "the only example in the world of a pure elected constituent assembly operating in parallel to the regular legislature in an existing, consolidated democratic polity"31.

Trata-se de um experimento complexo e não usual na história do constitucionalismo, que trouxe inúmeras dificuldades operativas no campo político, sobretudo no que se refere à isenção de interesses político-partidários dos membros do Parlamento - o que será observado com mais atenção no próximo tópico. Num sentido lato, pode-se dizer que trata-se da vontade, e da dificuldade,

30 É também evidente que o processo de participação por meio da internet também apresenta (e apresentou naquela situação) problemas específicos. Um deles é o acesso por toda a população à internet. Como explica Thorvaldur Gylfason e Anne Meuwese (Tradução nossa): "A primeira categoria de ferramentas compreendia os extensos aplicativos de mídia social usados ativamente pelo Conselho constitucional. Ao considerar isso, precisamos ter em mente que a redação ocorreu em meados de 2011, quando o uso de mídias sociais era um pouco diferente do que é hoje. A presença ativa nas mídias sociais ainda não era uma "característica obrigatória" para os atores da esfera pública, que se tornou apenas alguns anos depois. As mídias sociais já eram amplamente usadas por instituições políticas na Islândia, mas muitas vezes principalmente como fachada ou para fins de dispersão de informações na melhor das hipóteses. Na época, o uso desses fóruns para solicitar ativamente contribuições do público era uma característica inovadora. O Conselho constitucional empregou dois especialistas em informática para facilitar todos os aspectos técnicos do trabalho, incluindo o uso de mídias sociais. No entanto, os dois benefícios relacionados à participação popular também merecem ser mencionados. Um dos benefícios foi o sentimento de pertencimento encorajado pelo convite aberto ao público à participação, que ajudou a criar o sentimento de que se tratava de fato de uma lei constitucional para o povo e elaborada pelo povo. Esse sentimento coletivo pode ajudar muito a explicar o forte apoio ao projeto de Constituição no referendo de 2012. Outro benefício foi a mensagem clara de que grupos especiais de interesse não recebiam tratamento especial, uma mensagem que fortalecia o sentimento de participação popular". GYLFASON, Thorvadur; MEUWESE, Anne. Digital Tools and the Derailment of Iceland's New Constitution. CESifo Working Paper, n. 5997, category 2, Public Choice, july 2016. Também cabe ressaltar que recentemente a Assembleia Geral da Organização das Nações Unidas declarou o direito humano à internet, para aprofundamentos, ver: BURCKHART, Thiago. Direito, cultura e cidadania. Curitiba : Prismas, 2017.

31 Tradução nossa: "o único exemplo no mundo de uma assembleia nacional constituinte eleita que opera paralelamente à legislatura regular em uma política democrática existente e consolidada". RENWICK, Alan. After the referendum: options for a Constitutional Convention. London: The Constitution Society, 2014. p. 10. 
PETTERS MELO, Milena; BURCKHART, Thiago. Evoluções do constitucionalismo contemporâneo: a experiência de elaboração do projeto de constituição Islandesa de 2011. Revista Eletrônica Direito e Política, Programa de Pós-Graduação Stricto Sensu em Ciência Jurídica da UNIVALI, Itajaí, v.16, n.1, $1^{\circ}$ quadrimestre de 2021. Disponível em: www.univali.br/direitoepolitica - ISSN 1980-7791

de conciliar o constitucionalismo com a democracia a partir do funcionamento concomitante de dois órgãos representativos que visam ambos definir o destino político do país, mas sendo um, o Conselho Constitucional, dependente do outro, o Parlamento.

\section{MOTIVOS DO INSUCESSO NA PROMULGAÇÃO}

O processo de feitura da nova Constituição islandesa foi marcado por uma série de conflitos políticos. O parlamento islandês, após a admissão de erros no comando do país que resultaram na crise econômica de 2008, acatou os anseios sociais de redigir um novo texto constitucional no ano de 2009, elegendo um Comitê Constitucional composto por sete pessoas responsáveis pelo delineamento da Assembleia Nacional Constituinte. A referida Assembleia, organizada em 2010, contou com 25 membros eleitos diretamente pela população ${ }^{32}$.

Entretanto, após deliberações internas, a Assembleia Nacional Constituinte decidiu por trabalhar em dois temas considerados polêmicos para alguns representantes políticos do parlamento, quais sejam, a reforma eleitoral e a estatização dos recursos naturais. Como destaca Gylfason, tratam-se de interesses que contrastam com uma parcela dos representantes políticos do Parlamento. Nesse sentido, pouco antes da Assembleia Nacional Constituinte iniciar seus trabalhos em 2011, um grupo de indivíduos com ligação ao Partido da Independência (centro-direita) apresentou uma petição à Suprema Corte contestando o modo pelo qual a eleição para a Assembleia Constituinte havia sido conduzida.

A referida petição resultou na anulação da eleição que constituiu a Assembleia Nacional Constituinte pelo voto de seis ministros - sendo que cinco deles foram indicados pelo Partido da Independência. Desse modo, ficou ao encargo do Parlamento indicar 25 nomes para constituir um Conselho Constitucional, que seria responsável por redigir a Constituição. Ao Conselho foram indicados os anteriores vinte e cinco nomes que faziam parte da Assembleia, mas com a condição de que

${ }^{32}$ Cfe. GYLFASON, Thorvaldur. Democracy on Ice: a post-mortem of the icelandic Constitution. London: Open Democracy, 19 june 2013. 
PETTERS MELO, Milena; BURCKHART, Thiago. Evoluções do constitucionalismo contemporâneo: a experiência de elaboração do projeto de constituição Islandesa de 2011. Revista Eletrônica Direito e Política, Programa de Pós-Graduação Stricto Sensu em Ciência Jurídica da UNIVALI, Itajaí, v.16, n.1, 10 quadrimestre de 2021. Disponível em: www.univali.br/direitoepolitica - ISSN 1980-7791

a Constituição somente seria promulgada através do Parlamento e não diretamente pela Assembleia.

Nesse contexto, o Conselho Constitucional sofreu uma série de pressões políticas e oposição aos temas colocados em pauta. No entanto, em quatro meses o Conselho Constitucional produziu o Projeto de Constituição, tendo sido aprovado por unanimidade no Conselho e foi, posteriormente, encaminhado para aprovação do Parlamento em meados de $2011^{33}$. Assim:

During the period of its operation, Iceland's Constitutional Council appeared to offer an impressive model for a new type of constitution-making: democratic, freed from the leaden constraints of old party politics, crowd-sourced, modern. Today, however, Iceland's experience appears to be one of conspicuous failure: however meritorious the process might have been, it has not delivered any result. ${ }^{34}$

Posteriormente, a Constituição foi encaminhada para referendo popular no início de 2012. Como observa Gylfason, o Partido Independentista e membros do Partido Progressista conseguiram atrasar a realização do referendo até o mês de outubro, alegando não terem tido tempo suficiente para analisar o documento. No entanto, o texto constitucional foi aprovado por referendo popular por um total de $67 \%$ dos votos. Tendo isso em vista, o Parlamento optou por não operar nenhum tipo de reforma substantiva no projeto, alterando apenas algumas palavras com o intuito de dar maior clareza ao texto ${ }^{35}$.

Contudo, mesmo após a aprovação do Projeto de Constituição por referendo, uma série de críticas surgiram no meio acadêmico e na mídia impressa. Como também aponta Gylfason, "the criticism offered was generally of low quality on top of being

\footnotetext{
33 Tradução nossa: "No decorrer da preparação do projeto de Constituição, o conselho buscou e recebeu conselhos de inúmeros especialistas em diferentes áreas, bem como de cidadãos comuns que foram convidados a oferecer seus comentários e sugestões no site interativo do conselho. Alguns representantes de grupos de interesse especial, não acostumados a serem convidados para reuniões legislativas exclusivas, não responderam ao convite aberto ao público. Depois de concluídos os trabalhos, eles não poderiam objetá-lo com a desculpa de que não haviam sido consultados." Cfe. GYLFASON, Thorvaldur. Democracy on Ice. Op. Cit.

34 Tradução nossa: "No período de sua operação, o Conselho Constitucional islandês ofereceu um significativo modelo para um novo tipo de elaboração de Constituições: democrática, livre de restrições dos clássicos partidos políticos, feita pelo povo, moderna. Atualmente, entretanto, o experimento islandês parece ser um conspícuo erro: apesar de o processo ter sido meritório, não trouxe qualquer resultado". RENWICK, Alan. After the referendum: options for a Constitutional Convention. p. 64.
}

35 GYLFASON, Thorvaldur. Democracy on Ice. Op. Cit. 
PETTERS MELO, Milena; BURCKHART, Thiago. Evoluções do constitucionalismo contemporâneo: a experiência de elaboração do projeto de constituição Islandesa de 2011. Revista Eletrônica Direito e Política, Programa de Pós-Graduação Stricto Sensu em Ciência Jurídica da UNIVALI, Itajaí, v.16, n.1, 10 quadrimestre de 2021. Disponível em: www.univali.br/direitoepolitica - ISSN 1980-7791

late, reflecting personal opinions rather than academic research as well as total disregard for the timetable laid down by parliament"36. Essas críticas e construções argumentativas pós- referendo confluíram para a não aprovação imediata da nova Constituição islandesa pelo Parlamento. Nesse sentido:

[...] it should be remembered [...] that, whatever the merits of the Icelandic Constitutional Council's internal deliberations, its recommendations have not been implemented, despite popular support, because most politicians oppose them in part or whole. By taking the process out of the hands of politicians, it weakened political legitimacy ${ }^{37}$.

Essa discussão coloca o Projeto de Constituição ainda hoje como um "unfinished

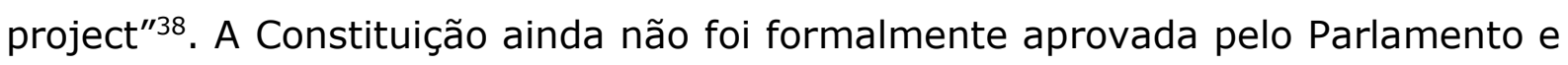
continua incerta a possibilidade, ou não, de sua aprovação. Muitos especialistas tem expressado preocupação com o fato de atualmente a crise econômica ter passado e as portas para a possível aprovação da nova Constituição estarem fechadas, pois sem crise não haveria nova Constituição ${ }^{39}$. No entanto, ainda existem esperanças de especialistas com relação à aprovação do projeto de Constituição pelo Parlamento ${ }^{40}$.

\footnotetext{
36 GYLFASON, Thorvaldur. Democracy on Ice. Op. Cit.

37 Tradução nossa: "deve ser lembrado [...] que, quaisquer que sejam os méritos das deliberações internas do Conselho Constitucional Islandês, suas recomendações não foram implementadas, apesar do apoio popular, porque a maioria dos políticos se opõe a elas em parte ou no todo. Ao tirar o processo das mãos dos políticos, enfraqueceu a legitimidade política". RENWICK, Alan. After the referendum: options for a Constitutional Convention. p. 73.

38 BERGMANN, Eirikur. Reconstituting Iceland: constitutional reform caught in a new critical order in the wake of crisis. Op. Cit.. p. 4.

39 Tradução nossa: "Alguns analistas expressaram a preocupação de que agora que a crise econômica da Islândia fora superada graças ao FMI e aos países nórdicos, a janela de oportunidade se encerrou: nenhuma crise, nenhuma constituição". GYLFASON, Thorvaldur. Iceland's citizen Constitution: the window remains wide open. Verfassungsblog, 06 abr 2016.

40 Argumenta Gylfason que (Tradução nossa): "A crise da Islândia não fora superada, longe disso. Esta semana assistiu-se à maior manifestação de sempre na Praça do Parlamento, com mais de vinte mil pessoas exigindo a demissão do governo na sequência do escândalo dos Panama Papers que envolve três dos doze ministros da Islândia. Tortola nas Ilhas Virgens Britânicas, que está no centro da tempestade, não é apenas um paraíso fiscal offshore. Pelo contrário, Tortola é praticamente sinônimo dos acontecimentos anteriores à quebra financeira da Islândia em 2008. Os Panama Papers mostram que o número de empresas offshore islandesas é quatro vezes superior ao número correspondente de empresas norueguesas, o que implica uma diferença de 60 vezes em termos per capita. A crise da Islândia é agora mais profunda do que nunca. Agora que as pessoas vêem - não apenas em casa, mas também na imprensa mundial - o que os principais oponentes da reforma constitucional têm feito, sua demanda pela ratificação da nova Constituição pelo Parlamento parece se intensificar. Uma nova pesquisa de opinião pós-Panamá papers feita pelo maior jornal da Islândia, Fréttablaðið, sugere que o apoio dos partidos do governo diminuiu de $51 \%$ nas eleições de 2013 para 30\% atualmente, enquanto o maior partido da oposição, os Piratas, cujo principal objetivo é para ratificar a nova constituição, viu o seu apoio subir de 5\% em 2013 para $43 \%$ atualmente. A
} 
PETTERS MELO, Milena; BURCKHART, Thiago. Evoluções do constitucionalismo contemporâneo: a experiência de elaboração do projeto de constituição Islandesa de 2011. Revista Eletrônica Direito e Política, Programa de Pós-Graduação Stricto Sensu em Ciência Jurídica da UNIVALI, Itajaí, v.16, n.1, 10 quadrimestre de 2021. Disponível em: www.univali.br/direitoepolitica - ISSN 1980-7791

Observa-se, portanto, que o processo de formulação da nova Constituição encontrou desde o seu início uma excessiva politização. Essa politização foi protagonizada pelas lideranças político-partidárias durante o processo. Neste caso específico, os interesses de parlamentares foram sobrepostos aos interesses da população que votou diretamente no referendo do texto constitucional. Há, evidentemente, uma clara discrepância na correspondência entre os anseios sociais e os interesses político-partidários de uma minoria política responsável pela aprovação da nova Constituição.

Esse debate remonta à discussão entre constitucionalismo e democracia e coloca a questão de calcular até que ponto a influência político-partidária pode ser benéfica num processo constituinte. De fato, todo processo constituinte democrático deve ser plural e prezar pela participação de diversos grupos sociais e políticos. No entanto, a monopolização do processo constituinte por parte de um partido - ou pelos interesses de um determinado partido ou conjunto de partidos - deslegitima o aspecto democrático que deve ser subjacente a esse debate, colocando em questão a representatividade na democracia representativa.

Nesse contexto, a experiência islandesa nos fornece uma série de elementos para reflexão sobre os limites entre o político e o jurídico, entre democracia e constitucionalismo, demonstrando que a excessiva politização pode trazer aspectos negativos para um saudável processo constituinte e para a consolidação de um sentimento constitucional que preze pelo bem-comum e pelo aprofundamento da experiência democrática. A aprovação do referido texto constitucional ainda continua sendo um impasse para a sociedade islandesa. Nas palavras de Thovaldur Gylfason, "the window remains wade open"41. No entanto, a crise política no país, como atesta Gylfason, aprofundou desde a publicação do escândalo de corrupção internacional Panama Papers, o que levantou novamente o debate sobre a aprovação do texto constitucional, atestando que a janela de oportunidades desse novo texto constitucional não está fechada.

janela de oportunidade não fechou; continua aberta". GYLFASON, Thorvaldur. Iceland's citizen Constitution: the window remains wide open. Verfassungsblog, 06 abr 2016.

41 Tradução nossa: "a janela permanence aberta". GYLFASON, Thorvaldur. Iceland's citizen Constitution: the window remains wide open. Op. Cit. 
PETTERS MELO, Milena; BURCKHART, Thiago. Evoluções do constitucionalismo contemporâneo: a experiência de elaboração do projeto de constituição Islandesa de 2011. Revista Eletrônica Direito e Política, Programa de Pós-Graduaç̧ão Stricto Sensu em Ciência Jurídica da UNIVALI, Itajaí, v.16, n.1, $1^{\circ}$ quadrimestre de 2021. Disponível em: www.univali.br/direitoepolitica - ISSN 1980-7791

\section{CONSIDERAÇÕES FINAIS}

O novo projeto de constituição islandesa evidencia uma série de inovações singulares no campo político-constitucional ao passo que também expressa uma profunda contradição: se por um lado houve uma massiva participação no seu processo de elaboração e consequente aprovação do texto por meio de referendo popular, por outro faltou pressão popular para a promulgação do texto pelo Althingi. Quais foram os fatores que levaram a uma queda qualitativa da participação popular em um período relativamente curto de tempo?

O processo evidencia que há a necessidade de se (re)pensar os limites da democracia representativa e da politização de base partidária nos processos constituintes. Até que ponto a participação de partidos e grupos de interesses pode não ser benéfica para a própria democracia? A excessiva partidarização das discussões, nesse processo em específico, pode levar ao definitivo insucesso na aprovação desse novo texto constitucional, rompendo com um processo essencialmente democrático.

Em efeito, apesar da indefinição quanto à aprovação, ou não, do texto constitucional e das contradições inerentes a esse processo, a elaboração desse novo documento deixou profícuos ensinamos para a história do constitucionalismo e se posiciona como uma experiência significativa para a política democrática e para o direito constitucional na contemporaneidade. A utilização de novos instrumentos, como o crowdsourcing, são de grande valia para se recuperar o sentido e a relação existente entre o constitucionalismo e a democracia. Ao mesmo tempo, o insucesso na aprovação da nova constituição impulsiona a refletir sobre grandes questões que se colocam para o constitucionalismo hodierno, estas questões se relacionam com os limites e a legitimidade da democracia representativa, e de forma mais aprofundada, e trágica, levanta o interrogativo sobre a real possibilidade de participação democrática na tomada de decisões sobre o modelo de desenvolvimento que se impõe de modo hegemônico na trilha dos processos de globalização econômica. 
PETTERS MELO, Milena; BURCKHART, Thiago. Evoluções do constitucionalismo contemporâneo: a experiência de elaboração do projeto de constituição Islandesa de 2011. Revista Eletrônica Direito e Política, Programa de Pós-Graduação Stricto Sensu em Ciência Jurídica da UNIVALI, Itajaí, v.16, n.1, $1^{\circ}$ quadrimestre de 2021. Disponível em: www.univali.br/direitoepolitica - ISSN 1980-7791

\section{REFERÊNCIAS DAS FONTES CITADAS}

ACKERMAN, Bruce. The Rise of World Constitutionalism. Virginia Law Review, v. 83, n. 4, p. 771-797, 1997.

ÁRNASON, Ágúst Thór. A Review of the Icelandic Constitution: popular sovereignty of political confusion. Tijdschrift voor Constitutioneel Recht, v. 2, n. 3, p. 342$351,2011$.

BARROSO, Luis Roberto. Neoconstitucionalismo e constitucionalização do Direito: o triunfo tardio do direito constitucional no Brasil. Revista de Direito Administrativo, Rio de Janeiro, v. 240, p. 1-42, abr. 2005.

BERGMANN, Eirikur. Reconstituting Iceland: constitutional reform caught in a new critical order in the wake of crisis. Working paper prepared in the conference Political Legitimacy and the Paradox of Regulation. Presented in the workshop Crowd-pleasers or key janglers? The impact of drops in political legitimacy on democratic reform and their consequences. Leiden University, January 24-25, 2013.

BOBBIO, Norberto. L'età dei diritti. Torino: Einaudi 1990.

BORON, Atillio. El neoliberalismo armado. In: SADER, Amir; GENTILLI, Pablo. La trama del neoliberalismo: mercado, crisis y exclusión social. CLACSO - Consejo Latinoamericano de Ciencias Sociailes: Buenos Aires, 2003.

BURCKHART, Thiago. Direito, cultura e cidadania. Curitiba : Prismas, 2017.

CASTELLS, Manuel. A sociedade em rede. $8^{a}$ ed. Trad. Roneide Venancio Majer. Rio de Janeiro: Paz e Terra, 2007.

CHAUÍ, Marilena. Uma nova classe trabalhadora. In: SADER, Emir. Lula e Dilma: 10 anos de governos pós-neoliberais no Brasil. Rio de Janeiro : Flacso, 2013.

DANIELSSON, Jon. The first casualty of the crisis: Iceland. In: FELTON, Andrew; REINHART, Carmem M. The First Global Financial Crisis of the $21^{\text {st }}$ Century. Centre of Economic Policy Reserch (cepr): A VoxEU.ogr Publication, London, 2008.

ELSTER, Jon. Forces and mechanisms in the Constitutional-Making process. Duke Law Journal, v. 45, n. 364, 1995.

GYLFASON, Thorvaldur. From collapse to Constitution: the case of Iceland. CESifo Working Paper n. 3770, 2013.

GYLFASON, Thorvaldur. Democracy on ice: a post-mortem of the icelandic Constitution. London, Open Democracy, 19 june 2013.

GYLFASON, Thorvadur; MEUWESE, Anne. Digital Tools and the Derailment of Iceland's New Constitution. CESifo Working Paper, n. 5997, category 2, Public Choice, july 2016. 
PETTERS MELO, Milena; BURCKHART, Thiago. Evoluções do constitucionalismo contemporâneo: a experiência de elaboração do projeto de constituição Islandesa de 2011. Revista Eletrônica Direito e Política, Programa de Pós-Graduação Stricto Sensu em Ciência Jurídica da UNIVALI, Itajaí, v.16, n.1, 10 quadrimestre de 2021. Disponível em: www.univali.br/direitoepolitica - ISSN 1980-7791

HARVEY, David. The enigma of capital: and the crisis of capitalism. London, Profile, 2010.

ISLÂNDIA, Ministério do Interior. Advertisement of the results of the referendum on 20 October 2012. Disponível em < http://www.kosning.is/thjodaratkvaedagreids/ur2012/english/nr/7993 >.

LANDAU, David. Constitution-Making Gone Wrong. Alabama Law Review, v. 64, n. 5, 2013.

LANDEMORE, Hélène. Inclusive Constitution-Making: the Icelandic experiment. Journal of Political Philosophy, Hoboken, v. 23, n. 2, pp. 166-191, 2015.

MELO, Milena Petters. As recentes evoluções do constitucionalismo na América Latina: neoconstitucionalismo? In WOLKMER, Antonio Carlos; MELO, Milena Petters (Org.). Constitucionalismo Latino-Americano: tendências contemporâneas. Curitiba: Juruá, 2013.

MONTEIRO, Hugo Bragança. Como a Islândia saiu da crise. Económico, Lisboa, 19 Out. 2012

MUEHLBRONNER, Kathrin. Iceland: outcome of referendum on Icesave likely to impact sovereign ratings. Global Sovereign, London, 23.feb.2013.

RENWICK, Alan. After the referendum: options for a Constitutional Convention. London: The Constitution Society, 2014.

SACHS, Ignacy. Caminhos para o desenvolvimento sustentável. Rio de Janeiro: Garamond, 2002.

SANTAYANA, Mauro. O plebiscito Islandês e o silêncio das mídias. Rio de Janeiro: Opera Mundi, 21 de outubro de 2012.

SANTOS, Milton. Por uma outra globalização. Editora Record: Rio de Janeiro, 2001.

WEISS, Braown (ed.). Chapter 12 in Environmental change and international law: New challenges and dimensions. Tokyo: United Nations University Press, 1992.

RECEBIDO EM: MAI/2020

APROVADO EM: SET/ 2020 